\title{
Perspectives
}

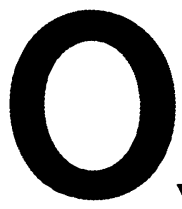

ver the past decade, work from many laboratories has led to a generally accepted hypothesis for the primary synthetic events that are involved in steroid hormone action. Although no universal agreement exists for the specific molecular details, the overall steps in the pathway have been elucidated.

Receptors for steroid hormones, initially described by Jensen and Jacob (1), are tissue-specific binding proteins for steroidal ligands that have high affinity (dissociation constant $\left[K_{\mathrm{d}}\right] \sim 10^{-10}$ M) for hormone and exist in low concentration $\left(2-6 \times 10^{4}\right.$ molecules) in target cells. Upon binding the entering hormone, the receptor appears to undergo an ill-defined "activation" reaction, which enhances the affinity of receptor for nuclear interphase chromosomes. The activated hormone receptor complex accumulates in the nucleus and is found bound to chromosomal DNA. Within 30 min, synthesis of new high molecular weight precursor to messenger RNA is initiated. The aggregate experimental evidence from many model systems and laboratories indicates that the level of DNA transcription is the primary focal point of steroid action in target cells. After accumulation of precursor mRNA, these molecules are processed in a complex splicing reaction so that all intervening sequence (intron) RNA is removed. At this point the mature mRNA can now relocate to the cytoplasm, attach to ribosomes, and code for the hormonemediated synthesis of enzymes and structural or secretory proteins (2-5).

In the chick oviduct, a series of investigations designed to define the pathway for progesterone (and estrogen) effects on egg-white protein (e.g., ovalbumin, ovomucoid, and avidin) synthesis has led us to postulate the specific sequence of events shown summarized above and shown in Fig. 1 (6-8).

It has been postulated that hormones act primarily at the level of DNA transcription from the following lines of evidence. Hormone-receptor complexes accumulate in the nuclear compartment and bind to chromosomal DNA with high affinity. Steroid-regulatable genes contain sequences in their 5'-flanking regions that preferentially bind receptors with an affinity greater than average DNA $(9,10)$. Removal of these 5 '-flanking se-

Received for publication 10 April 1984.

J. Clin. Invest.

(C) The American Society for Clinical Investigation, Inc.

0021-9738/84/08/0307/06 \$1.00

Volume 74, August 1984, 307-312

\section{Steroid Hormone Action in Eucaryotic Cells}

\author{
Bert W. O'Malley \\ Baylor College of Medicine, Houston, Texas 77030
}

quences prevents induction of gene expression by steroid hormones (11-13). Precursor mRNA and mature mRNA both accumulate in response to steroid hormone action. After accumulation of steroid hormone receptors on the nuclear chromosomes, radiolabeling experiments have demonstrated that synthesis of nascent pre-mRNA is stimulated (14-16). Thus, although steroids can have an effect on mRNA half-life under certain conditions, their primary action appears to occur at the DNA or transcription level.

In chick oviduct cells, we have reported the existence of a receptor complex composed of two hormone-binding subunits $(8,17,18)$ (Fig. 1). Subunit A $(79,000 \mathrm{~mol} \mathrm{wt})$, which binds to deproteinized DNA with high affinity $\left(K_{d} \sim 10^{-10} \mathrm{M}\right)$, is considered to be the "effector" subunit $(19,20)$. Subunit B $(105,000$ mol wt), which binds to interphase chromosomes $\left(K_{\mathrm{d}} \sim 5 \times 10^{-9}\right.$ $\mathrm{M})$, has been postulated to play a "specifier" or catalytic role in chromosomal localization of hormone-receptor complex (16). The structural proof and structure-function speculations have been published in detail previously $(19,21)$. It is noteworthy that a similar subunit structure has been reported recently for the progesterone receptor in human cultured cells (22). Nevertheless, it seems clear that the receptors for separate classes of steroid hormones are structurally distinct, although certain properties are common to all.

In the present review, I wish to emphasize the complexity of steroid hormone action at the level of the intact cell. I suggest that steroid hormone regulation of gene expression may require a series of coordinate structural interactions that occur at least at four separate levels of cellular organization. Due to the length restrictions and purpose of this review, this is not meant to be comprehensive relative to the totality of publications in the field of steroid hormone action.

In the chick oviduct, we have characterized four genes (ovalbumin, $\mathrm{X}, \mathrm{Y}$, and ovomucoid) in terms of their primary structure and inducibility in response to hormone administration. The ovalbumin gene has been sequenced completely together with its surrounding genomic regions (23-25). Our more recent evidence suggests that the ovalbumin gene contains certain sequences in its adjacent 5 -flanking region that are considered to be important for both accurate and efficient expression. Accurate initiation of transcription of the ovalbumin gene appears to be influenced primarily by the TATATAT box located at -32 base pairs upstream from the first nucleotide $(+1)$ of the structural gene. This A-T-rich heptamer acts as a specifier sequence in 


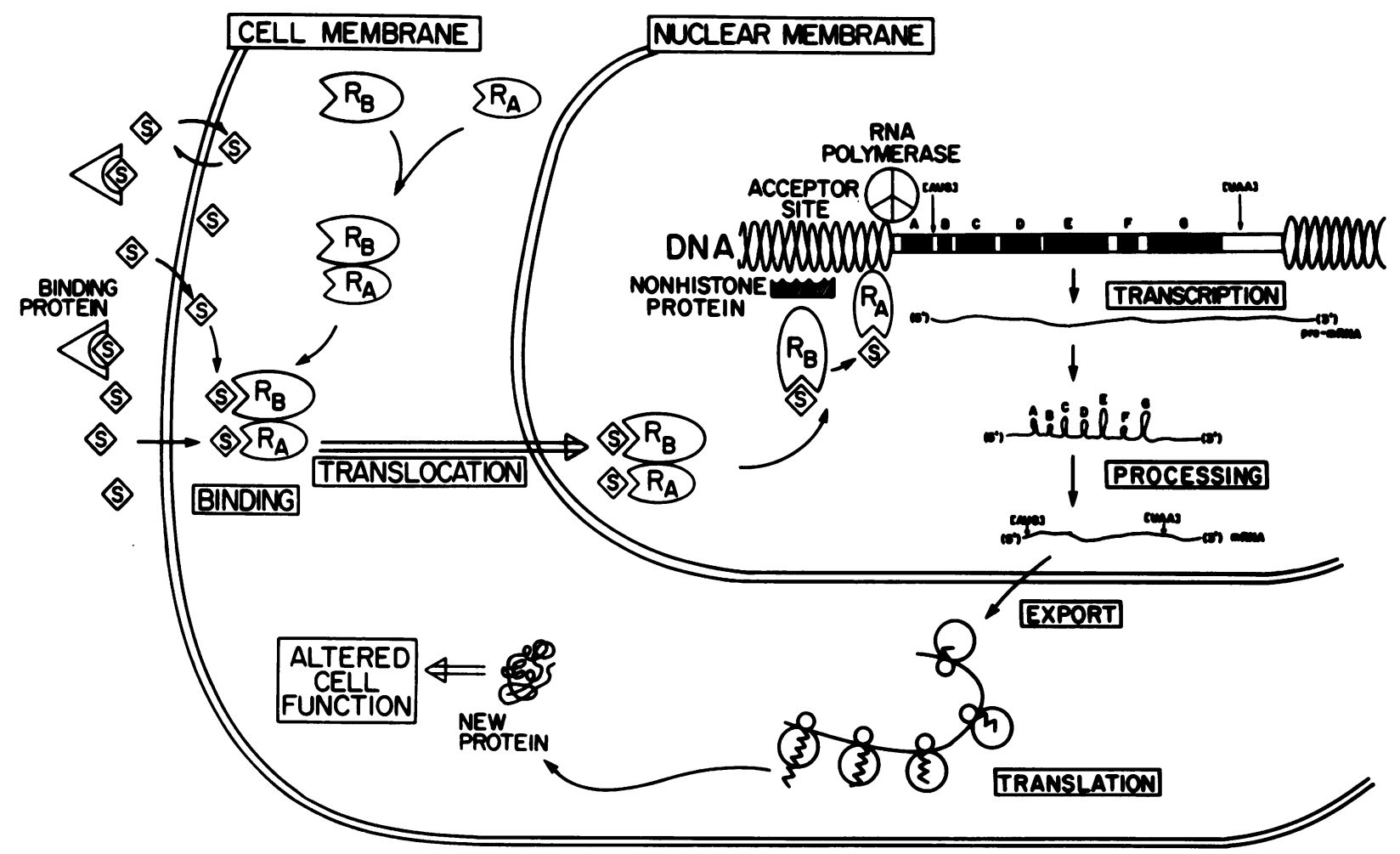

Figure 1. Schematic representation of the pathway for steroid hormone action in a eucaryotic cell (e.g., chicken oviduct). In this scheme, progesterone binds to the receptor complex and it interacts with interphase chromosomes, presumably at or near the 5 '-flanking DNA of regulatable genes. Gene activation occurs and a large precur-

that it directs RNA polymerase II to initiate transcription at the proper site located 32 bases downstream. If as little as a single base pair is changed to a G-C within the TATA box, accurate transcription is abolished $(26,27)$. This result is supported by similar observations in a number of other laboratories for a variety of genes (26).

Although the TATA box may be considered as a part of the eucaryotic promoter region, it can be no more than one of the sequence participants because it does not have a great capacity to modulate the rate of gene transcription. In fact, sequences located slightly further upstream from the TATA box ( -95 to -48) form an important part of the basal promoter. The "hormone control" region, however, appears to be structurally separate and is located further upstream $(-222$ to -95$)$. These regions are shown schematically in Fig. 2 and the experimental evidence for this hypothesis is discussed in more detail below. Finally, we have attempted to ascertain the importance of steroid receptor-DNA interactions in the hormone-regulatable induction of ovalbumin gene expression. Toward this end, we have searched for DNA sequences that might display a capacity to preferentially attract steroid receptors. In fact, such a region has been identified within this hormone control region $(-200$ to sor mRNA is synthesized. This precursor is spliced and processed (introns removed) and the mature mRNA is transported to the cytoplasm where it is translated on ribosomes, which produces the designated protein. $S$, steroid hormone; $R_{A}$ and $R_{B}$, receptors $A$ and $B$.

$-150)$ for the ovalbumin gene (10) and is shown also in Fig. 2. This region of the genome binds the A subunit of the progesterone receptor of chick oviduct with an order of magnitude higher affinity as compared with other nonspecific DNA sequences.

Of major interest have been the results of our recent experiments designed to determine the region of 5'-flanking se-

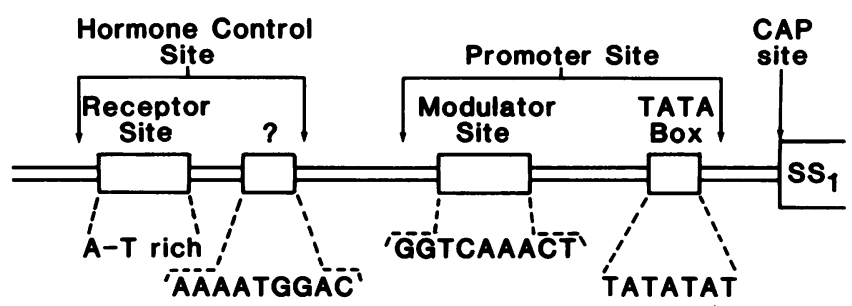

Figure 2. Structural features of the ovalbumin gene are shown, which depict the structural gene (including intervening sequences) and the distinct hormone control site and promoter that comprise the upstream regulatory region in the 5 -flanking region of the gene. CAP, first structural nucleotide; $\mathbf{S S}_{1}$, specific site 1 . 
quence near the ovalbumin gene that is required for hormonemediated induction of transcription of this gene. We have used a tissue culture transfection system in which an ovalbuminglobin fusion gene (ovalglobin) cloned together with SV40 and plasmid sequences is used to transiently transfect cells in culture $(12,28)$. This "fusion" gene consists of the 5 '-region of the chicken ovalbumin gene $(-753$ to +41$)$ and the structural region of the chicken $\beta$-globin gene $(+115$ to $+1,479)$ (see Fig. 3 ). We found this experimental model satisfactory because it used a homologous hybrid gene of small size, which should produce a globin transcript that is easily identifiable in untransformed oviduct cells after in vitro transfer experiments. Since it still retains the putative ovalbumin promoter, we could systematically alter the 5'-flanking sequences and monitor their regulatory potential after reintroduction into oviduct cells. Finally, the same recombinant contains the SV40 early region genes for T-antigen, which are not hormonally regulated and serve as an internal control for quantification in acute gene transfer experiments.

Transfection of the ovalglobin gene into untransformed, primary monolayer cultures of oviduct tubular gland cells led to a significant $(5-20 \times)$ induction of ovalglobin RNA when progesterone was added to the culture. Deletion of critical 5'flanking sequences near the gene abolished the induction. The results have been described in detail elsewhere $(12,28)$. Oviduct cells in primary monolayer culture were exposed to either intact ovalglobin $(-753)$ or deletion constructs in which all but 323 , 222 , or 95 nucleotides of 5 -flanking sequence of ovalbumin gene had been removed. Half of the cultures were then exposed to progesterone. The presence of progesterone stimulated accumulation of transcripts of the intact ovalglobin gene. Deletion of all upstream sequences $\left(5^{\prime}\right)$ of -95 eliminated the progesterone-mediated induction of transcripts. In contrast, deletion of sequences located only $5^{\prime}$ to -222 still allowed regulation of transcription by progesterone as did another deletion to -323 . Neither the deletions themselves nor the presence of progesterone had any effect on the level of SV40 early gene transcripts.

These experiments indicated that the removal of upstream sequences in the region of -95 to -222 lead to the elimination of the capacity to respond to hormone (Fig. 2). It was of considerable interest that the sequences containing both the capacity to respond to hormone and the preferential DNA binding site for receptor were located within this same region of the genome (10, 29; and Compton, J. G., W. T. Schrader, and B. W. O'Malley, submitted for publication).

As mentioned above, the entire picture relating to steroid hormone regulation of gene expression cannot be explained by even the most explicit definition of receptors and primary DNA structure. We need to understand why the same receptors do not regulate the same gene sequences in different cells. To clarify this "nuclear capacity" to respond to hormones, we were required

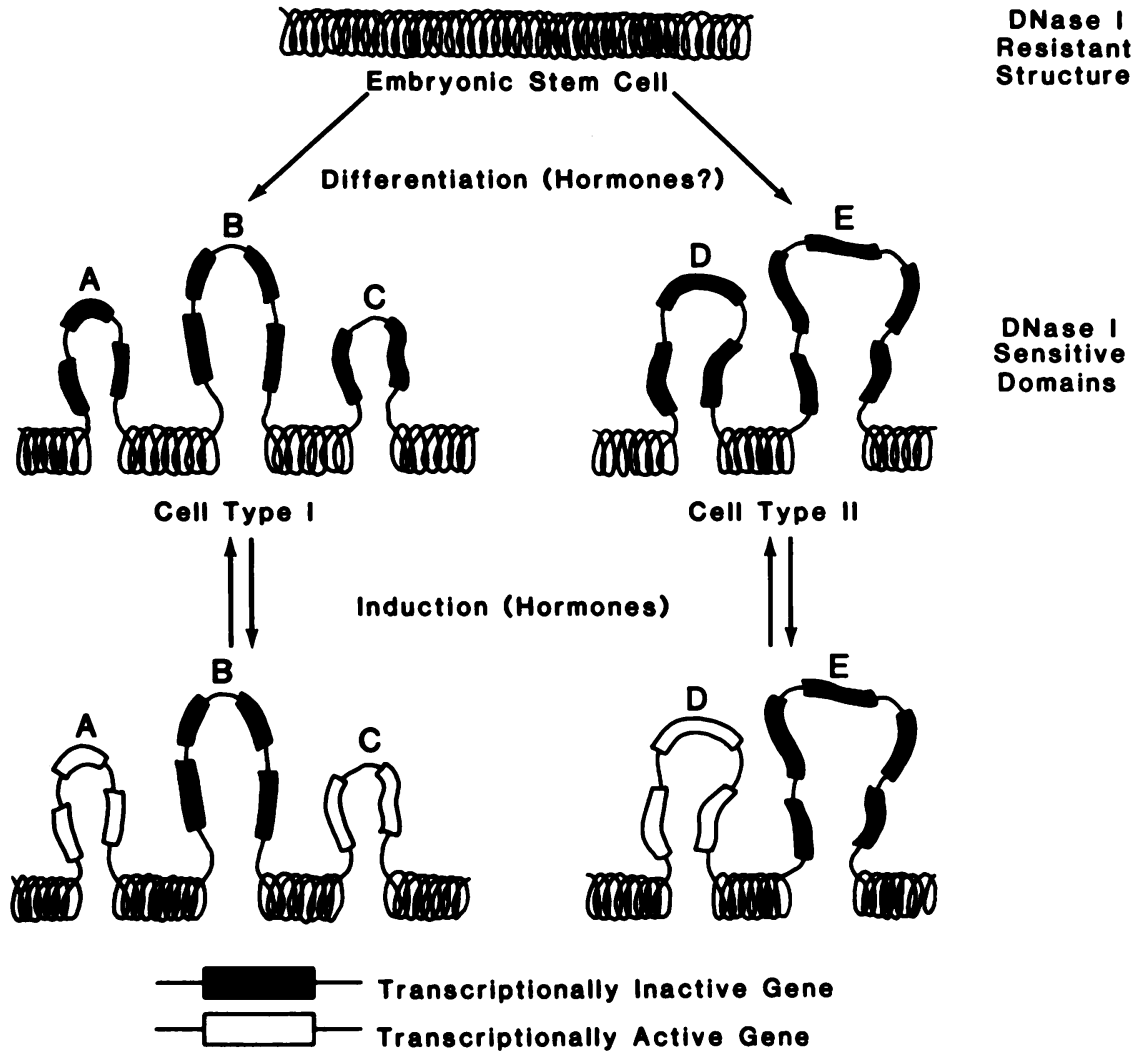

Figure 3. Relationship between cell differentiation and DNase I sensitivity of tissue-specific genes. In the differentiated states, all genes having the "capacity" to be turned on should exist in an "open" or more accessible structure (DNase I-sensitive domains). Subsequent interactions with regulatory molecules, such as hormone-receptor complexes, can then induce regulation of transcription by interacting with the 5 -regulatory elements of the genes. 
to use a biochemical probe that could reliably distinguish various higher order structural states of eucaryotic interphase chromosomes. To this end, we used the DNase I digestion assay (30) to determine structural differences in the genomic area that contained the ovalbumin gene family relative to other cells in which these same genes are not expressed. This work has been published in detail elsewhere (31-33) and only will be summarized to illustrate conceptual points.

Approximately 100 kilobases (kb) of DNA containing and surrounding the ovalbumin family of $(\mathrm{X}, \mathrm{Y}, \mathrm{OV})$ genes exhibit a preferential sensitivity to DNase I in the chromatin of oviduct cells. In other tissues where these three genes are not expressed, no such preferential sensitivity is observed. We interpret this to mean that in cells where these genes are to be expressed the surrounding chromatin DNA in this $100-\mathrm{kb}$ domain is packaged differently from the majority of the DNA in the bulk of the chromatin (Fig. 3).

The fact that a gene is in a DNase I-sensitive or more "open" chromatin state is not entirely sufficient for it to be actively transcribed. This is demonstrated by the fact that the DNase I sensitivity of the entire domain persists in nuclei isolated from hormonally withdrawn chicks in spite of the shutdown of ovalbumin gene transcription. An analogous result was obtained for the globin gene itself in transcriptionally inactive erythrocytes. Therefore, DNase I sensitivity appears to reflect a more accessible chromatin structure which in turn relates to the developmental capacity of a cell to express the gene in question. It can be viewed as a necessary but not wholly sufficient step in the prior commitment of a cell to allow a certain gene to be expressed. Such a mechanism would make it possible for distinct cell types to respond to a single inducer each in its own individual and distinctive manner.

In other words, all genes which are ever to be expressed in a given cell must be contained within these unraveled or accessible regions of chromatin at the time of terminal differentiation. The chromosomal domains appear to be related to molecular differentiation since they are tissue-specific and "irreversible." The DNA that is not contained in these domains could be passively packaged into a more complex higher-order structure by histones. The DNA in such a higher-order structure, the majority of DNA in each cell type, would be unavailable for interactions with regulatory molecules. The containment of such genes in these structures only provides the "capacity" for expression. Once included in this "expressible" domain, it is now accessible to regulatory factors or influences such as hormone-receptor complexes (Fig. 3).

Finally, it would be appropriate to conclude by discussing an even more complex structural interaction of cellular genes and genomic domains with the nuclear matrix $(34,35)$. In a series of recently published experiments, we have investigated the possibility that selected regions of genomic DNA might be attached to the nuclear matrix or nucleo-skeleton. The nuclear matrix is a fibrillar proteinaceous skeleton that appears to form a structural support for the nucleus with its contents. It may be analogous to the cytoskeleton of the cytoplasm. Although the nuclear matrix has not been rigorously defined in biochemical or cell biological terms, its potential importance in DNA synthesis $(34,36)$, and processing of mRNA precursors (37) has been documented. In recent experiments, we questioned whether the differential structural attachment of genomic sequences might cause these sequences to be made more or less available to the transcriptional apparatus.

In fact, we found that all the actively transcribed gene sequences that we tested were associated with the nuclear matrix, while nontranscribed sequences were localized in unattached chromatin structures and could be released by restriction nuclease treatment $(38,39)$. This conclusion is consistent with the idea that the nucleus is a highly organized organelle and that transcription may occur on a matrix structure rather than free in solution. This attachment to the matrix could either facilitate transcription of DNA by RNA polymerase or it may be a concomitant of transcription. Cessation of transcription in the presence of actinomycin D does not itself lead to release of genes from the matrix.

It is interesting to note that steroid hormone receptors also have been found associated with salt-insoluble nuclear subfractions and the nuclear matrix $(40,41)$. Upon hormonal withdrawal the receptors were no longer associated with the nuclear matrix. Although receptors could play some role in the attachment of the inducible genes to the nuclear matrix, it is unlikely that the receptor is the sole protein component binding the active gene to the matrix structure.

In conclusion, it is fair to speculate that the cellular forces involved in steroid hormone induction of gene expression are complex indeed. These parameters are summarized in Fig. 4. At the present time, our best guess on the major structural determinants for induction are as follows: $(a)$ steroid receptor is the obligatory and active intermediate to transduce the informational signal inherent in the hormone to the regulatable gene; $(b)$ the linear sequence of the gene itself is of obvious importance since it not only contains the inherited structural code for the protein, but it appears to contain structurally distinct "promoter" and "regulatory" sequences, the latter of which both binds receptor and determines the maximal rate of hormone-induced gene expression; $(c)$ inducible genes are contained within large structurally distinct (DNase I-sensitive) domains that are an index of molecular differentiation and that are likely to maintain the capacity of genes to respond to inductive influences; and $(d)$ the chromatin itself undergoes a specific attachment to the nuclear matrix so that actively expressed regions of these domains appear to be more firmly bound, and perhaps, more easily transcribed by the nuclear transcriptive apparatus. This picture is only complicated further by consideration of other potentially important levels of substructure such as modification of primary DNA sequence (e.g., methylation and ZDNA) and chromatin fine structure (DNase hypersensitivity).

It appears safe to speculate that only by obtaining more precise structural and functional information on each of these 


\section{Receptor}

\section{Gene (Promoter)}

\section{Chromosome (Domains)}

\section{Nucleus (Matrix?)}
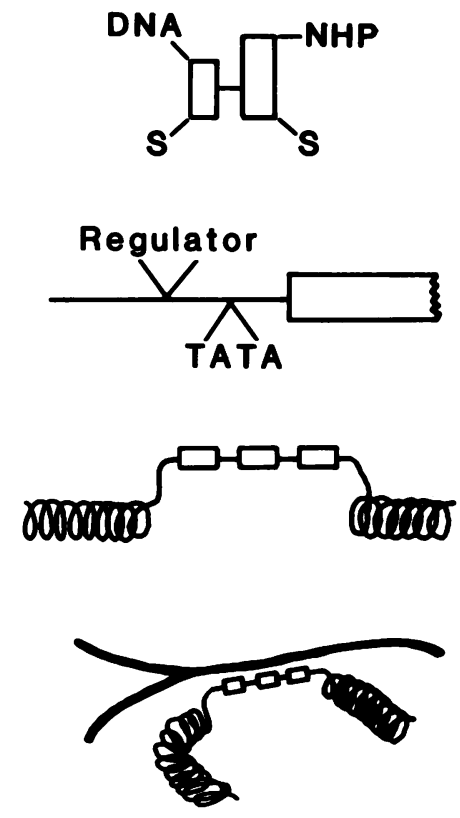

Figure 4. Schematic representation of the structural determinants for hormonal induction of gene expression. These include the steroid hormone receptor, the gene and its regulatory elements, the chromosomal domain, and the nuclear matrix. levels of regulation can we understand completely the molecular mechanism of steroid hormone action. To accomplish this task, a continued application of the combined technologies of molecular biology and cell biology will most certainly be required.

\section{References}

1. Jensen, E. V., and H. I. Jacobson. 1962. Recent Prog. Horm. Res. 18:387.

2. Ringold, G., K. R. Yamamoto, J. M. Bishop, and H. E. Varmus. 1977. Proc. Natl. Acad. Sci. USA. 74:2879.

3. Harris, S. E., J. M. Rosen, A. R. Means, and B. W. O'Malley. 1975. Biochemistry. 14:2072.

4. Chan, L., A. R. Means, and B. W. O'Malley. 1973. Proc. Natl. Acad. Sci. USA. 70:1870.

5. Rhoads, R. E., G. S. McKnight, and R. T. Shinke. 1971. J. Biol. Chem. 246:7407.

6. O'Malley, B. W., W. L. McGuire, P. O. Kohler, and S. G. Korenman. 1969. Recent Prog. Horm. Res. 25:105.

7. O'Malley, B. W., D. R. Roop, E. C. Lai, J. L. Nordstrom, J. F. Catterall, G. E. Swaneck, D. A. Colbert, M.-J. Tsai, A. Dugaiczyk, and S. L. C. Woo. 1979. Recent Prog. Horm. Res. 35:1.

8. Schrader, W. T., M. E. Birnbaumer, M. R. Hughes, N. L. Weigel, W. W. Grody, and B. W. O'Malley. 1981. Recent Prog. Horm. Res. 37:583.

9. Payvar, F., O. Wrange, J. Carlstedt-Duke, S. Okret, J. A. Gustafasson, and K. R. Yamamoto. 1981. Proc. Natl. Acad. Sci. USA. 78:6628.

10. Compton, J. G., W. T. Schrader, and B. W. O'Malley. 1983. Proc. Natl. Acad. Sci. USA. 80:16.

11. Hynes, N., A. J. J. van Ooyen, N. Kennedy, P. Herrlich, H. Ponta, and B. Groner. 1983. Proc. Natl. Acad. Sci. USA. 80:3637.
12. Dean, D. C., B. J. Knoll, M. E. Riser, and B. W. O'Malley. 1983. Nature (Lond.). 305:551.

13. Renkawitz, R., H. Bueg, T. Graf, P. Mathias, M. Grez, and G. Schutz. 1982. Cell. 31:167.

14. Ringold, G. M., K. R. Yamamoto, G. M. Tomkins, J. M. Bishop, and H. E. Varmus. 1975. Cell. 6:299.

15. Swaneck, G. E., J. L. Nordstrom, F. Kreutzaler, M.-J. Tsai, and B. W. O'Malley. 1979. Proc. Natl. Acad. Sci. USA. 76:1049.

16. McKnight, G. S., P. Pennequin, and R. T. Schimke. 1975. J. Biol. Chem. 250:8105.

17. Schrader, W. T., and B. W. O'Malley. 1972. J. Biol. Chem. 247:51

18. Sherman, M. R., P. L. Corvol, and B. W. O'Malley. 1970. J. Biol. Chem. 245:6084.

19. O'Malley, B. W., T. C. Spelsberg, W. T. Schrader, F. Chytil, and A. W. Steggles. 1972. Nature (Lond.). 235:141.

20. Spelsberg, T. C., A. W. Steggles, F. Chytil, and B. W. O'Malley. 1972. J. Biol. Chem. 247:1368.

21. Grody, W., W. T. Schrader, and B. W. O'Malley. 1982. Endocr. Rev. 3:141.

22. Lessey, B. A., P. S. Alexander, and K. B. Horwitz. 1983. Endocrinology. 112:1267.

23. Woo, S. L. C., W. G. Beattie, J. F. Catterall, A. Dugaiczyk, R. Staden, G. G. Brownlee, and B. W. O'Malley. 1981. Biochemistry. 20:6437.

24. Dugaiczyk, A., S. L. C. Woo, E. C. Lai, M. L. Mace, Jr., L. McReynolds, and B. W. O'Malley. 1978. Nature (Lond.). 274:328.

25. Breathnach, R., J. L. Mandel, and P. Chambon. 1977. Nature (Lond.). 270:314.

26. Corden, J., B. Waslylyk, A. Buchalder, P. Sassone-Corsi, C. Kedinger, and P. Chambon. 1980. Science (USA). 209:1406.

27. Zarucki-Schulz, T., S. Y. Tsai, K. Itakura, X. Soberon, R. B. 
Wallace, M.-J. Tsai, S. L. C. Woo, and B. W. O'Malley. 1982. J. Biol. Chem. 257:11070.

28. Knoll, B. J., T. Zarucki-Schulz, D. C. Dean, and B. W. O'Malley. 1983. Nucl. Acid Res. 11:6733.

29. Davidson, E. H., H. T. Jacobs, and R. J. Britten. 1983. Nature (Lond.). 301:468.

30. Weintraub, H., and M. Groudine. 1976. Science (USA). 93:848.

31. Lawson, G. M., B. J. Knoll, C. J. March, S. L. C. Woo, M.-J. Tsai, and B. W. O'Malley. 1982. J. Biol. Chem. 257:1501.

32. Stumph, W. E., M. Baez, W. G. Beattie, M.-J. Tsai, and B. W. O'Malley. 1983. Biochemistry. 22:306.

33. Alevy, M. C., M.-J. Tsai, and B. W. O’Malley. 1984. Biochemistry. 23:2309.
34. Berezney, R., and D. S. Coffey. 1974. Biochem. Biophys. Res. Commun. 60:1410.

35. Capco, D. G., K. M. Wan, and S. Penman. 1982. Cell. 29:847.

36. Robinson, S. I., B. D. Nolkin, and B. Vogelstein. 1982. Cell. 28:99.

37. Ciejek, E. M., J. L. Nordstrom, M.-J. Tsai, and B. W. O'Malley. 1982. Biochemistry. 21:4945.

38. Paulson, J. R., and U. K. Laemmli. 1977. Cell. 12:817.

39. Ciejek, E. M., M.-J. Tsai, and B. W. O'Malley. 1983. Nature (Lond.). 306:604.

40. Clark, J. H., and E. J. Peck, Jr. 1976. Nature (Lond.). 260:635.

41. Barrack, E. R., and D. S. Coffey. 1980. J. Biol. Chem. 255:7265. 